\title{
코칭리더십과 혁신행동의 관계에서 조직신뢰의 매개효과와 권력거리성향의 조절된 매개효과
}

\author{
박 선 규 정 은 경 $^{+}$
}

강원대학교 행정·심리학부 심리학전공

\begin{abstract}
본 연구의 목적은 코칭리더십이 조직신뢰와 혁신행동에 미치는 영향과 권력거리성향의 수준 에 따라 그 양상이 달라지는 것을 밝히는데 있다. 이에 따라 코칭리더십과 혁신행동의 관계 를 살펴보았고 코칭리더십이 혁신행동에 미치는 영향에 있어서 조직신뢰의 매개효과를 확인 하였다. 그리고 조직신뢰가 혁신행동에 영향을 미치는데 있어 권력거리성향의 조절효과를 확인하였다. 마지막으로, 코칭리더십과 혁신행동의 관계를 조직신뢰가 매개하는데 있어 권력 거리성향의 조절된 매개효과를 검증하였다. 이를 위해 국내의 인터넷 설문조사 업체 엠브레 인을 통해 국내 직장인 697 명의 자료를 수집하였다. 연구결과, 코칭리더십과 혁신행동 간의 관계를 조직신뢰가 유의미하게 매개하여 부분매개효과가 있는 것으로 검증되었다. 권력거리 성향의 조절효과와 조절된 매개효과 또한 모두 유의미한 것으로 나타났다. 조직신뢰가 낮은 수준에서는 권력거리성향이 낮은 구성원이 권력거리성향이 높은 구성원보다 혁신행동을 더 욱 많이 했지만, 조직신뢰가 높은 수준에서는 그 차이가 유의미하게 준 것으로 확인됐다. 마 지막으로, 본 연구에서는 이러한 연구결과를 통해 나온 실무적 시사점, 한계점 및 추후 연구 의 제언을 논의하였다.
\end{abstract}

주제어 : 코칭리더십, 조직신뢰, 혁신행동, 권력거리성향, 조절된 매개효과

† 교신저자 : 정은경, 강원대학교 행정·심리학부 심리학전공, E-mail: ekchung@kangwon.ac.kr 
최근 코로나 19 사태로 인해 기업은 혁신의 시기를 맞이했다. 화상회의, 재택근무, 유연근 무제 등 대부분의 기업에서 수년간 미뤄오던 업무 혁신을 몇 개월 만에 이뤄내고 있다 (MONEYTODAY, 2020). 이는 예측 불가능하고 빠르게 변화하는 외부환경에 대응하는데에는 기업의 혁신이 선택이 아니라 필수임을 시사 한다. 특히 기존의 기업환경과는 완전히 다른 4 차 산업의 시대로 들어가면서 기업의 혁신은 더욱 중요해지고 있는데, 기업의 혁신은 종업 원들 개인의 혁신행동에서 시작되므로 종업원 의 혁신행동이 기업의 생존과 성장에 매우 중 요하다.

불확실한 경영환경 속에서 직원들의 혁신행 동을 이끌어내기 위해서는 리더의 역할이 매 우 중요한데, 단순히 직원들의 수행을 높이는 것이 아니라 구체적 혁신행동을 이끌어내기 위해서는 기존의 전통적 리더십에는 다소 한 계가 있다(Scott \& Bruce, 1994), 직원들의 자발 적 행동변화를 일으키기 위한 리더십으로 최 근에는 코칭리더십이 주목을 받고 있다. 코칭 리더십이란, 리더가 상명하달식의 의사결정을 하는 것이 아닌, 구성원의 역량 및 의견을 중 심으로 하여 방향제시, 개발, 피드백을 제공 해주고, 신뢰로운 관계를 맺기 위해 노력하는 것이다(Stowell, 1986). 기업 외부환경의 급속한 변화로 불안해하는 종업원이 해야할 일을 스 스로 찾을 수 있도록 돕고(Francesca \& Dan, 2020), 일의 의미를 재구성할 수 있도록 하는 것은 조직의 결과변인에 영향을 미칠 수 있기 때문에 코칭리더십은 시대에 적합한 리더십 유형이라 할 수 있다(Yang, Lee, \& Lee, 2015; Lee, 2018). 실제로, Sung와 $\operatorname{Tak}(2017)$ 의 연구에 서 코칭리더십은 창의적인 결과물을 창출하는 데 긍정적인 영향을 미치는 것으로 나타났다.
또한, 코칭리더십의 특성 중 하나인 구성원에 게 문제를 해결할 능력이 있음을 믿고 그들이 주도적으로 업무를 구성하도록 권한을 부여하 는 것은 혁신행동을 높이는데 영향을 미치는 것으로 나타나(Pieterse et al., 2010) 코칭리더십 이 혁신행동에 긍정적인 영향을 미칠 가능성 을 보여주었다.

더불어, 현대의 조직은 수직적인 문화보다 수평적인 문화의 중요성이 강조되며 구성원 개개인의 의견과 의사결정이 중요시되고 있다. 코칭리더십은 신뢰를 바탕으로 리더와 구성원 의 수평적 관계를 추구하고 역량개발을 통해 스스로 성과를 달성할 수 있도록 독려한다는 점에서 시대에 적합한 리더십 유형이라 할 수 있다(Yang, Lee, \& Lee, 2015). 따라서, 여러 가 지 시대적 요구를 반영한 코칭리더십은 종업 원의 자율적 사고와 행동을 유도한다는 면에 서 혁신적인 성과를 창출하는데 정적인 영향 을 미칠 것으로 기대된다. 특히, 코칭리더십은 리더와 구성원간의 신뢰적인 관계를 중요시 하기(Park, Yoon, 2018) 때문에 종업원의 조직 신뢰에 정적인 영향을 미칠 것으로 예상된다. 그러나, 코칭리더십을 독립변수로 한 연구들 이 다수 존재함에도, Park \& Yoon(2018)이 지 적한 바와 같이 코칭리더십과 종속변인간 매 개변인으로써 조직신뢰의 역할에 대한 연구는 미흡한 실정이다.

한편, 시대적인 요구로 수평적인 기업문화 가 확산되고 있기는 하나 조직 내에는 리더의 지시와 감독에 순응하기를 원하는 구성원들도 여전히 있다. 이들은 수직적인 체계를 선호하 므로, 본인의 의견을 주장하거나 능력을 발휘 하려고 앞장서기보다 상사가 직접적으로 해야 할 일을 하달해주는 것을 선호한다. 이러한 개인의 성향은 '권력거리성향'으로 살펴볼 수 
있는데, 권력거리성향이란 Hofstede(1980)가 전 세계의 문화적 가치에 대한 인식 차이를 연구 하여 고안한 5가지 문화차원(권력거리, 개인대 집단, 불확실성회피, 남성성-여성성, 장기-단기 지향성) 중 하나인 '권력거리' 개념에서 파생 되었다. 권력거리가 높을수록 조직내 불평등 한 권력의 분배를 용인하기 때문에 리더의 권 위를 인정하고 리더의 일방적인 의사결정을 기대한다. 반면에, 권력거리가 낮을수록 구성 원 간 평등한 권력의 분배를 지향하기 때문에 의사결정 과정에 적극적으로 참여하기를 바란 다. 이러한 권력거리성향은 자발적인 위험감 수를 핵심으로 하는 혁신행동에 중요한 영향 을 미칠 수 있으며 권력거리성향이 높은 구성 원일수록 새롭고 혁신적인 행동이 나오기 어 렵다(Kim \& Zhou, 2018).

상기한 논의를 종합하여, 본 연구는 현대 사회에서 점점 더 중요해지고 있는 종업원의 혁신행동에 리더의 코칭리더십이 어떤 영향을 미치는지를 알아보고자 하였다. 아울러 리더 의 코칭리더십과 혁신행동간의 관계에 대한 매개변인과 조절변인의 효과도 함께 살펴보았 는데, 선행연구를 바탕으로 조직신뢰를 매개 변인으로, 권력거리성향을 조절변인으로 상정 하고 조절된 매개효과 모델을 검증하고자 하 였다.

\section{코칭리더십}

20세기 후반 코칭이 비즈니스 영역에서 활 발하게 이루어지면서 코칭적 철학이나 기법 을을 적용한 코칭리더십 개념이 제안되었다. Stowell(1986)은 조직구성원들을 대상으로 심층 적인 인터뷰를 진행하여 48개의 코칭역량을 추출하였고, 이를 근거로 하여 코칭리더십을
이루는 네 가지의 구성요소(방향제시, 개발, 수행평가, 관계)를 제시하였다. 방향제시는 구 성원이 설정한 목표가 조직의 목표와 일치하 는가를 점검하고 지향해야 할 목적을 설명하 는 것이고, 개발은 구성원의 역량, 지식, 기술 등을 지속적으로 성장시켜 나갈 수 있도록 도 와주는 것이다. 수행평가는 구성원이 자율적 으로 정한 업무에 대해 구체적이고 객관적으 로 평가하는 것이고, 관계는 리더와 구성원이 신뢰를 기반으로 하여 수평적인 의사소통 관 계를 맺는 것을 말한다. 이외에도 코칭리더십 의 연구가 진행되며 여러 학자들이 코칭리더 십에 대해 정의하였다.

예를 들어, Ellinger와 Bostrom(1999)은 질문하 기, 장애물 제거, 물러서기, 피드백, 학습촉진 등 13 가지의 코칭역량을 권한부여 행동과 촉진행동 두 가지로 종합하여 코칭리더십의 구성요소로 규정하였다. 이후, 후속연구에서 Ellinger, Ellinger와 Keller(2003)는 질문 제시, 장 애물 제거, 피드백 제공, 피드백 요청, 기대설 정, 관점 바꾸기, 관점 넓히기, 예시 활용하기 등의 8 가지 코칭역량으로 구성된 코칭리더십 리더들의 코칭행위 척도를 제시하였다.

한편, Heslin, Vandewalle와 Latham (2006)은 지도, 촉진, 영감을 구성원들의 성과를 이끌어 내는 코칭리더십 리더의 세 가지 코칭행위 요 소로 제시하였다. 명확한 기대와 성과를 위한 의사소통, 건설적인 피드백, 구성원이 스스로 문제를 해결하고 분석할 수 있도록 돕는 것, 그리고 구성원의 잠재력을 발견할 수 있도록 영감을 주는 것으로 리더의 코칭리더십 행위 를 설명하였다.

Park, Yang와 McLean(2008)은 McLean(2005)이 코칭적 리더의 코칭역량으로 제시한 열린 의 사소통, 팀 접근, 인적 가치평가, 모호함 받아 
들이기 등의 네 가지 구성 요인에 개발촉진을 추가하여 총 다섯 가지의 코칭역량을 제시하 기도 하였다.

국내에서는 Jo와 $\operatorname{Tak}(2011)$ 가 조직적 맥락에 맞도록 코칭리더십의 척도를 개발하여 코칭리 더십의 구성 요인으로 존중, 목표제시와 피드 백, 관점변화 그리고 성장가능성에 대한 믿음 을 제시하였으며, 코칭리더십을 “조직 구성원 이 업무를 수행시 자신의 강점을 지각하고 개 발하여 조직의 성과를 높일 수 있도록 성장과 발전을 촉진하는 리더십”이라고 정의하였다.

상기한 코칭리더십의 구성요소와 정의를 종 합해보면 구성원과의 수평적인 의사소통을 강 조하고 구성원의 잠재된 능력을 믿고 이를 개 발할 수 있도록 분명한 목표설정과 함께 구체 적인 피드백을 제공하는 것이 코칭리더십의 핵심임을 알 수 있다.

이러한 코칭리더십의 개념은 다른 리더십 개념 중 임파워링 리더십과 유사한 부분이 있 다. 임파워링 리더십은 구성원에게 권한을 위 임하고, 의사결정에 직접 참여하도록 하며 구 성원 개인의 역량을 증진시키는데 목적을 둔 리더십이다(Kwon, \& Kwon, 2015; Thomas \& Velthouse, 1990). Arnold(2000)는 임파워링 리더 십을 좀 더 체계적으로 5 가지 하위요인으로 나누었는데 솔선수범, 코칭, 참여적 의사결정, 정보제공, 관심표출 등으로 제시하였다. 이외 에도 Konczak, stelly와 Trusty는 임파워링 리더 십을 권한위임, 책임성 확보, 자기주도적 의사 결정 장려, 정보공유, 기술개발, 혁신적 성과 를 위한 코칭 등의 하위요인을 제시하였다. 제시된 임파워링 리더십의 하위요인을 살펴보 면, 코칭이 포함되어 있음을 알 수 있다. 역으 로, 코칭리더십 또한 구성원의 자율성을 강조 하고 리더가 이를 지원해준다는 점에서 임파
워먼트의 개념과 관련되어 있음을 알 수 있다 (Sung \& Tak, 2017). 그러나 임파워링 리더십과 코칭리더십은 강조하는 바가 다르다. 코칭리 더십은 구성원 개개인의 능력을 믿어주고 이 를 개발시키는데 초점이 있는 반면, 임파워링 리더십은 권한의 위임함으로써 구성원에게 활 력과 주인의식을 가지도록하고(임경호, 2017), 역할을 공고히 하는 것을 강조한다(Drucker, 1988).

국내의 코칭리더십에 대한 연구 동향을 살 펴보면, 결과변수에 대한 코칭리더십의 직접 효과를 밝히는 연구는 비교적 활발하게 이루 어지고 있으나(Liu, 2016; Jo, 2016; Hwang, 2017), 조절효과와 매개효과와 같이 코칭리더 십의 작동 기제 등을 규명하는 논문은 다른 리더십 이론에 비해 아직까지 부족한 상태이 다. 또한, 조직몰입 혹은 조직시민행동과 같은 조직 수준에서의 성과 변인을 사용한 경우가 많고 개인의 성과에 대한 연구는 그다지 많지 않았다(Kang \& Jung, 2019).

이에 본 연구는 코칭리더십과 개인의 결과 변인 중 하나인 혁신행동 간의 관계를 매개 및 조절변인을 포함하여 살펴보고자 한다.

\section{코칭리더십과 혁신행동}

West와 $\operatorname{Farr}(1989)$ 는 혁신행동은 구성원이 유래없던 것을 의도적으로 창조하거나 새로운 아이디어와 상품, 프로세스를 역할과 조직에 적용하는 것이라 정의하였다. 이어서 Kanter (1988), Scot \& Bruce(1994)와 Janssen(2000)은 혁 신행동을 새로운 아이디어의 창출과 도입 그 리고 실현까지 아우르는 복합적인 개념이라고 정의하였다. Janssen(2000)은 좀 더 세분화하여 혁신행동을 세 단계로 분류하였다. 첫째, 아이 
디어의 개발로, 업무와 관련한 문제점, 불일치, 새로운 트렌드의 출현 등을 파악하여 이에 적 용할 수 있는 기발하고 유용한 아이디어를 고 안하는 것을 말한다. 둘째, 아이디어의 홍보이 다. 이는 개발한 아이디어가 실행될 수 있도 록 도와줄 수 있는 동료, 상사, 조직에게 적극 적으로 알리는 것을 말한다. 마지막 단계로, 아이디어의 실행이 있다. 고안한 아이디어가 조직, 팀, 개인의 역할에 완벽히 적용되어 성 과향상에 도움이 될 수 있도록 모델의 시제품 을 선보이는 것이다. 이후 수정, 보완하며 검 증을 받는 과정을 거치게 된다.

혁신행동과 유사한 개념으로 창의적 행동이 연구되기도 한다. 창의적 행동은 일반적으로 개인 혹은 집단에서 새롭고 유용한 아이디어 를 만들어내는 것이라 정의된다(Amabile, 1996). 반면에 혁신행동은 참신하고 유용한 아이디어 의 생성뿐만 아니라 이를 조직과 업무에 적용 하는 것을 포함하기 때문에(Shalley et al. 2004; Zhou, 2003) 창의적 행동은 혁신행동의 한 유 형이라 볼 수 있다. 창의적 행동에 비하여 혁 신행동은 아이디어가 실현되어 실제 가치를 발휘하는가를 나타낸다.

급변하는 기업환경 속에서 구성원들은 자 신에게 주어진 임무를 수행하는 것뿐만 아니 라 새로운 가치를 창출해야 한다는 점에서 혁신행동을 촉진하는 것은 조직의 중요한 관 심사이다. 구성원의 혁신행동이 촉진되는 환 경적 특성을 살펴보면, 먼저 리더의 신뢰이다 (Livingston, 1969; Yuan \& Woodman, 2010). 리 더가 구성원을 믿어줄 때 구성원은 안전감 을 느끼게 되고 혁신행동은 증가한다. 또한, 구성원의 의사결정에 대한 권한과 자율성 부여도 구성원의 혁신행동 촉진에 필수적 이다(Gotgrove \& Box, 1970; Pelz \& Andrews,
1966). 리더가 구성원에게 피드백을 자주하는 것 또한 구성원의 창의성과 혁신행동을 높이 는데 중요한 요인이 된다(Glassman, 1986). Battistelli (2013)는 직무에 대한 피드백을 제 공하는 경우 혁신행동에 직접적으로 정적 영 향을 미치는데 특히, 자율성이 높을 때 더욱 효과가 크다고 하였다. 조직문화 측면에서는 구성원의 기회와 성장을 촉진하는 개발문화 가 혁신행동을 높이는 것으로 나타났다(Choi, Park, \& Sun, 2011).

상기한 혁신행동을 높이는 특성들은 코칭 리더십의 성격과 유사한 측면이 있다. 코칭리 더십 역시 구성원의 잠재가능성을 믿어주고 스스로 문제해결을 할 수 있도록 도와주는 것 과 그에 맞는 자율성을 부여하고 신뢰를 바탕 으로 한 관계를 중요시하기 때문이다(Sung \& $\mathrm{Tak}, 2017)$. 실제로 Raza(2017)는 리더가 코칭리 더십을 발휘하여, 구성원에게 빠른 피드백을 주고, 명확한 목표를 갖게 하며 개발의 기회 를 제공하는 것이 혁신행동을 높인다는 것을 발견하였다. Wang(2013)의 연구에서는 관리자 의 코칭행동이 구성원의 혁신 능력을 자극하 여, 생산성 증가와 혁신행동에 영향을 주는 것으로 나타났다. 그 밖에도 $\operatorname{Kim}(2011)$ 은 혁신 행동을 높이기 위해서 리더는 평소 구성원에 게 관심을 가지고 의사소통하는 노력을 통해, 구성원에게 필요한 새로운 관점과 아이디어를 독려할 필요가 있음을 강조하여 코칭리더십의 하위요소인 의사소통이 혁신행동을 촉진할 수 있음을 제시하였다. Park와 Sohn(2009)의 연구 에서는 코칭의 또 다른 하위 요인인 임파워링 이 구성원의 혁신성향에 영향을 미치는 것으 로 확인되었다. 또한, 개발촉진이라는 코칭리 더십 하위요인은 리더의 학습지향성과 그 개 념이 유사한데, 리더의 학습지향성은 구성원 
들의 학습을 장려하고 의견을 적극적으로 반 영하는 것으로 구성원의 혁신성을 높이는데 긍정적 영향을 미치는 것으로 나타났다(Yoo, 2012). 이외에도 코칭리더십이 혁신행동에 긍정적인 영향을 미치는 연구들(Zhang, 2020; Dai, 2019; Park, 2018; Wang, 2013; Min, 2012; Kwon, 2013)이 확인되었고, 이러한 연구들은 코칭리더십이 혁신행동에 긍정적인 영향을 미 칠 가능성을 시사하고 있다.

상기한 선행연구에 기반하여, 본 연구에서 는 코칭리더십이 혁신행동에 긍정적인 영향을 주는지를 다시 한번 확인하고자 한다.

가설 1: 코칭리더십과 혁신행동은 정적 관 계를 가질 것이다.

\section{조직신뢰의 매개효과}

조직신뢰란 한 구성원이 다른 구성원 혹은 조직에게 가지는 마음으로, 감시나 통제가 없 어도 자신에게 마땅히 기대되는 행동을 할 것 이라는 기대하에 기꺼이 위험을 감수하려는 의지를 말한다(Mayer, Davis, \& Shoorman, 1995). 또한, Johnson-George와 Swap(1982)은 대부분의 신뢰 개념의 공통적 특징으로 위험을 감수하 려는 성향을 꼽았다. Tan \& $\operatorname{Tan}(2000)$ 은 조직 신뢰를 조직이 구성원에게 이익이 되는 쪽 으로 행동할 것이며 적어도 피해를 주지 않 을 것이라는 확신이라고 정의하였다. 이러한 신뢰의 대상은 상사, 동료, 조직, 경영진 등 여러 계층으로 형성될 수 있다(Lee, 2015). Fox(1974)와 McCauley \& Kuhnert(1992)는 대상에 따라 수직적 신뢰, 수평적 신뢰, 제도적 신뢰 로 분류하였다. 수직적 신뢰는 리더 혹은 상 사와 구성원 간에 형성되는 신뢰이고, 수평적
신뢰는 동료 간의 신뢰를 말한다. 제도적 신 뢰는 조직의 규범과 운영방침에 대한 신뢰를 말한다.

이러한 조직신뢰에 긍정적인 기여를 할 수 있는 변인으로 코칭리더십을 들 수 있다. Choi, Park, \& Sun(2011)는 인적 자원을 중요시 하고 구성원의 참여와 개발을 강조하는 조직 문화와 조직신뢰간에 높은 상관관계가 존재함 을 보고하였다. 상기한 특성들은 코칭리더십 의 핵심 하위 요소인 방향제시와 개발과 유사 하기 때문에 우리는 코칭리더십과 조직신뢰 간의 긍정적인 관계를 유추해볼 수 있다. 실 제로, Anderson(2009)은 리더의 코칭 행위를 통 한 코칭문화 조성이 구성원들을 더욱 개방적 이고 참여적으로 함으로써 조직신뢰를 높인다 고 보고하였다. 더하여, 코칭리더십의 하위 요 소인 관계는 리더와 구성원이 얼마나 신뢰로 운 관계를 가지고 있는가를 나타내는 것으로 (Stowell, 1986), 코칭리더십과 조직신뢰의 긍정 적인 관계를 생각해볼 수 있다. 또한, Jo(2011) 은 코칭리더십과 상사에 대한 신뢰 간의 유의 미한 정적 관계를 발견하였고, $\operatorname{Park}(2018)$ 의 연 구에서도 코칭리더십과 조직몰입의 관계를 조 직신뢰가 매개한다고 보고되었다. 코칭리더십 이 구성원들과의 신뢰적인 관계를 기반으로 하여 구성원의 능력을 믿고 이를 지원해준다 는 특성(Stowell, 1986)과 선행연구들의 결과를 고려하면, 코칭리더십이 조직신뢰에 긍정적인 영향을 미칠 수 있음을 알 수 있다. 코칭리더 십의 하위 요인별 특성이 조직신뢰에 긍정적 인 영향을 미칠 수 있음을 상기의 논의를 통 해 알 수 있으며 코칭리더십이 신뢰에 어떠한 영향을 미치는지에 대해 직접적으로 살펴본 연구들도 존재한다(Park, 2018; Park, 2016; Kim, 2013; Oh, 2012). 이러한 연구결과들을 기반으 
로 볼 때, 본 연구모델에서도 코칭리더십은 조 직신뢰에 긍정적인 역할을 미칠 것으로 예상 된다.

더불어, 조직신뢰는 조직의 성과변인에 큰 영향을 미친다. McCauley \& Kuhnert(1992)와 Tan \& $\operatorname{Tan}(2000)$ 은 조직신뢰 만큼 조직에 영향을 미치는 변인을 없을 것이라고 주장하며, 조직 신뢰가 현대 조직이론의 핵심 변인이라고 하 였다. Kim와 Lee(2002) 역시 조직에 신뢰가 형 성되면 조직에 대한 헌신과 몰입, 창의성 등 이 유발되므로 조직신뢰는 조직의 성과를 높 이는 핵심 자원이라 주장하였다. 여러 가지 조직성과 변인 중, 본 연구의 관심사는 혁신 행동이기 때문에 조직신뢰와 혁신행동 간의 관계를 살펴보려 한다.

조직신뢰는 구성원들이 위험을 감수할 수 있도록 하고 외부환경에 대해서 안전감을 느끼게 한다(Costa, 2003). 더하여 구성원들이 가진 지식과 아이디어를 다른 구성원에게 공유하려는 성향이 강해져 결국 그들의 업 무에 새로운 관점을 적용할 수 있도록 한다 (Edmondson, 1999). 또한, Aryee et al.(2002)은 조 직 신뢰가 조직 정체성에 영향을 미쳐 구성원 이 더욱 열심히 일하고 조직 내 다른 구성원 에게 협력적으로 행동하게끔 한다고 주장하였 다. 이는 구성원끼리 아이디어를 활발하게 공 유하여 결국엔 더 많은 아이디어를 생성할 수 있도록 영감을 준다(Yu, 2017). Kang(2020)의 연구에서 조직에 대한 신뢰는 구성원들로 하 여금 주인의식을 갖게 하여 혁신행동에 더욱 적극적으로 참여하도록 한다고 주장하였다. 이외에도 조직신뢰와 혁신행동의 관계는 여러 연구에서 검증 되었다(Song \& Kim, 2010; Song, 2019; We, Kim, \& Ryu, 2018).

상기한 이론적 배경을 바탕으로, 본 연구에
서는 조직신뢰가 코칭리더십과 혁신행동의 사 이를 매개하는지를 살펴보고자 한다.

가설 2: 조직신뢰는 코칭리더십과 혁신행동 의 관계를 매개할 것이다.

\section{권력거리성향의 조절효과}

Hofstede(1980)는 권력거리를 '한 국가나 사 회에서 권력을 갖지 못한 구성원들이 불평등 한 권력의 분배를 얼마나 수용하는가로 정의 하였다. 현재 이러한 정의가 가장 널리 쓰이고 있으며, 심리학 및 조직행동과 같은 사회과학 분야에서 주로 연구되고 있다(Smith, 2002). 이러한 권력거리는 대개 국가나 집단 차원에 서 연구되어왔다. 이에 Kirkman(2009)은 한 집 단에는 다양한 문화를 가진 개인들이 모여있 기 때문에, 효과적인 관리를 위해선 개개인의 문화적 특성을 고려해야 한다고 주장하며 개 인의 권력거리를 나타내는 권력거리성향(power distance orientation)을 제시하였다.

일반적으로 권력거리성향이 높은 구성원들 은 리더의 의견에 도전하는 것을 꺼리며 리더 에게 복종하는 경향이 있다(Hofstede, 2001). 또 한, 구성원들은 자신의 의사결정에 결점이 있 다고 생각하고, 리더에게는 더욱 우월한 점이 있다고 생각하여 리더의 의사결정을 믿는다 (Javidan et al., 2006). 따라서 리더의 결정을 더 욱 공정하고 합리적이라고 생각한다(Gudykunst \& Ting-Toomey, 1988). 반면, 권력거리 수준이 낮은 구성원들은 상사의 불공정함에 대해 적 극적으로 대처하고(Goodwin \& Goodwin, 1999), 자신의 의견을 표현하고 싶어한다(Hofstede, 2001).

이러한 권력거리성향은 그 수준에 따라 조 
직의 여러 가지 결과변인에 다양하게 영향을 미친다. 예를 들어, Sue-Chan와 Ong(2002)의 연 구에서 권력거리성향이 높은 구성원들은 업무 할당이 일방적으로 이루어지든 참여적으로 이 루어지든 성과에 차이가 나타나지 않은 반면, 권력거리성향이 낮은 구성원들은 업무할당에 적극적으로 참여했을 때 더욱 높은 수행을 보였다. 이처럼 권력거리성향과 결과변인들 간의 직접적 관계를 살펴본 연구들도 있으나 (Jeong \& Chung, 2019; Kim \& Chung, 2018; Guo, 2018; Lee \& Kim, 2017), 많은 연구들은 개인차 변인으로써 권력거리성향의 조절효과 에 좀 더 초점을 맞추고 있다. Farh, J. L., Hackett, R. D.와 Liang, J.(2007)의 연구에서는 지각된 조직지원과 직무성과의 관계에서 권력 거리가 높은 수준일 때 정적 상관을 보였지만, 권력거리가 낮은 수준에서는 부적 관계를 나타냈다. 국내의 연구에서는 심리적 임파워 먼트 경험이 조직몰입에 미치는 영향이 유의 미한 가운데 권력거리성향이 높은 구성원의 경우, 그 정도가 낮게 나타났고(Lee \& Jeon, 2016), Kim과 Moon(2019)의 연구에서는 포용적 리더십과 심리적 안점감의 관계에서 권력거리 의 조절효과가 나타났는데, 연구의 초기 가설 과는 다르게 포용적 리더십과 심리적 안전감 의 관계에서 권력거리 수준이 높은 경우 심리 적 안전감이 더욱 높았으며, 그 조절효과도 크게 나타났다.

조직신뢰와 혁신행동간의 관계에서도 권력 거리성향은 조절변인으로 작용할 수 있다. 몇 몇 선행연구들은 각종 조직관련 독립변인과 혁신행동 간의 관계를 구성원의 권력거리성향 이 조절한다는 것을 밝히고 있다. 예를 들어, Rauniyar, K, Ding, D.와 Rauniyar, N.(2017)의 연 구에서 상사의 비인격적 감독이 구성원의 창
의성에 영향을 줄 때, 높은 권력거리성향을 가진 구성원에게는 비인격적감독의 수준에 관 계없이 창의성이 동일하였지만, 낮은 권력거 리성향을 가진 구성원들은 상사의 비인격적 감독이 낮을 경우에 창의성이 증가하였다. 또 한, $\operatorname{Kim}(2018)$ 의 연구에서는 구성원의 주도적 성격이 혁신행동에 긍정적 영향을 미치는 관 계에서 권력거리 수준이 낮을수록 그 영향력 이 더 높음을 발견하였다.

본 연구의 관심사인 혁신행동과의 관계를 살펴보면, $\operatorname{Park}(2021)$ 의 연구에서 구성원의 권 력거리의 지각 정도가 높을수록 혁신행동이 낮아지는 것으로 나타났다. 그 이유는 권력거 리 성향이 높은 구성원은 조직의 불평등한 권 력구조를 받아들이기 때문에 상사와 부당한 지시에도 수긍하려는 경향이 있어, 심리적 안 점감이 저하(Appelbaum, 2019)되고 직무 스트레 스를 높게 지각(Jeong \& Chung, 2019)하기 때 문이다. 낮은 심리적 안전감과 높은 직무 스 트레스는 혁신행동에 부정적인 영향을 미치게 된다(Kark \& Carmeli, 2009; Kim, 2005). 심리적 안전감이란 한 구성원이 자신의 행동이나 말 로 인해 발생할 부정적인 결과에 대한 두려움 없이 자신을 표현할 수 있는 믿음(Edmondson, 1999)이라고 정의된다. 이러한 심리적 안전감 은 조직신뢰의 핵심개념인 기꺼이 위험을 감 수하려는 의지와 상통하는 바가 있다. 기꺼이 위험을 감수하려고 한다는 것은 부정적 결과 에 대한 두려움이 적다는 것을 뜻하기 때문이 다. 그러므로, 권력거리성향이 혁신행동에 부 정적 영향을 미치는 관계에서 조직신뢰가 높 은 경우라면 그 영향이 달라질 수 있음을 유 추할 수 있다.

따라서, 본 연구에서는 상기한 연구들을 바 탕으로 조직신뢰가 혁신행동에 미치는 영향을 


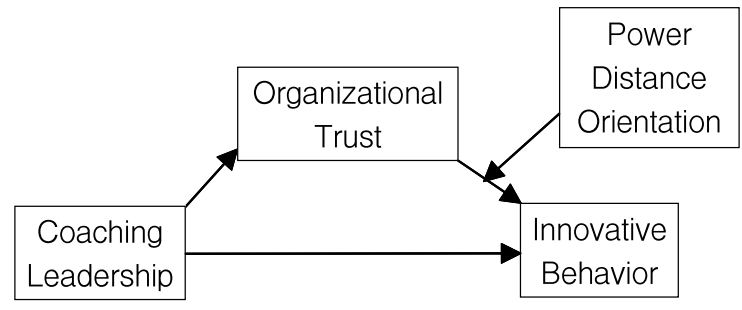

Figure 1. Research Model

권력거리성향이 조절하는지를 알아보고자 한 다. 아울러 위에서 제시한 조직신뢰의 매개효 과 모델을 권력거리성향이 조절하는지도 살펴 보고자 한다. 본 연구의 연구모델은 그림 1 에 제시되어 있다.

가설 3: 권력거리성향은 조직신뢰와 혁신행 동의 관계를 조절할 것이다.

가설 4: 코칭리더십이 조직신뢰를 통해 혁 신행동에 미치는 영향에서 권력거리성향의 조 절된 매개효과가 나타날 것이다.

\section{방 법}

\section{조사대상 및 자료수집}

본 연구는 온라인 설문조사 업체를 통해 실 시되었다. 불성실한 응답을 한 설문을 제외하 기 위해 문항에 대한 답이 정해져 있는 1 개의 문항을 추가하였다(“이 문항에 매우 그렇지 않 음을 선택해주시기 바랍니다.”). 잘못된 응답을 하거나 불성실한 응답을 한 문항을 제외하였 다. 총 1077 명의 응답자 중 380 명의 참여자가 불성실 응답으로 제외되었고, 697명의 데이터
가 최종 분석에 사용되었다.

표본의 성별은 남자가 272명(39\%), 여자 가 425 명(61\%)이었고, 나이는 평균 39.71세 $(S D=10.27)$ 로 20 대가 169 명(24.2\%), 30대 172명 (24.7\%), 40대 179명(25.7\%), 50대가 177 명 (25.4\%)로 균등하게 구성되어있다. 학력은 고 졸 이하가 76 명(10.9\%), 전문대졸 129명(18.5\%), 대학교 재학 35 명(5\%), 대졸 375 명(53.8\%), 대 학원졸 71 명 $(10.2 \%)$ 로 대졸이 가장 많았다. 회 사의 계열은 서비스업이 429명(61.5\%), 제조업 239명(34.3\%), 금융업 29명(4.2\%)이었고, 직급은 사원이 265명(38\%), 대리 149명(21.4\%), 과장 134 명(19.2\%), 차장 51명(7.3\%), 부장 98명 $(14.1 \%)$ 이었다.

\section{측정 도구}

\section{상사의 코칭리더십}

상사의 코칭리더십을 측정하기 위해 Stowell, J. S.(1986)가 개발한 13 문항을 사용하였다. 4 개 의 하위요인으로 구성되어 있으며, 방향제시 3 문항, 개발 3 문항, 수행평가 3 문항, 관계 4 문 항이다. 문항의 예는 "나의 상사는 내가 달성 해야 할 구체적 업무 목표를 스스로 세우도록 도와준다."와 같다. 5점 척도로 측정되었고 $(1=$ 매우 그렇지 않다, $5=$ 매우 그렇다), 본 연구에 
서 척도의 Cronbach Alpha Coefficient는 .952으 로 나타났다.

\section{조직신뢰}

조직신뢰를 측정하기 위해 Cook, J., Wall, T. (1980)이 개발한 8문항을 사용하였다. 문항의 예시로는 "우리 기업은 항상 나를 공정하게 대우하려고 노력한다.”등이 있다. 문항은 7점 척도로 측정되었고 $(1=$ 매우 그렇지 않다, $7=$ 매 우 그렇다), Cronbach Alpha Coefficient는 .954로 나타났다.

\section{혁신행동}

혁신행동을 측정하기 위해 Scott \& Bruce (1994)이 개발하고 Janssen(2000)에 의해 보완된 9문항을 사용하였다. 척도는 아이디어 개발 3 문항, 아이디어 홍보 3 문항, 아이디어 실행 3 문항, 총 3 개 하위요인으로 구성되어 있다. 문 항의 예는 "나는 업무와 관련된 어려운 문제 를 해결하기 위해 새로운 아이디어를 개발한 다.”이다. 문항은 5 점 척도로 측정되었고 $(1=$ 매 우 그렇지 않다, $7=$ 매우 그렇다), Cronbach Alpha Coefficient는 .923으로 나타났다.

\section{권력거리성향}

권력거리성향을 측정하기 위해 Dorfman, P. W. \& Howell, J. P.(1988)이 개발한 6문항을 사 용하였다. 기존의 Hofstede(1980)의 권력거리 척 도가 국가 수준의 집단적 문화차이를 측정한 반면, 본 연구의 척도는 개인의 권력거리를 측정하기에 더욱 적합한 척도라 할 수 있다. 문항의 예시는 "리더는 부하의 의견을 자주 묻지 말아야 한다.”와 같다. 문항은 5점 척도 로 측정되었고 $(1=$ 매우 그렇지 않다, $5=$ 매우 그렇다), Cronbach Alpha Coefficient는 .710으로
나타났다.

\section{통제변인}

본 연구에서는 선행연구에서 혁신행동과의 관계가 정적으로 유의한 것으로 보고된 직급 을(Volmer, Spurk \& Niessen, 2012) 통제변인으로 사용하였다.

\section{분석 방법}

가설검증을 위해 SPSS 24.0과 PROCESS Macro 3.4.1(Hayes, A. F., 2018)을 사용하였다. 먼저, 인구통계학적 특성과 변인 간의 상관관 계를 분석하였다. 그리고 측정도구의 타당성 을 확인하기 위해 신뢰도 분석과 확인적 요인 분석을 실시하였다. 이후 가설 1 을 알아보기 위해 SPSS 24.0의 선형회귀분석을 통해 위계적 회귀분석을 이용하였다. 가설 2 을 알아보기 위해 PROCESS MACRO의 Model 4을 이용하여 매개효과를 검증하였다. 이어서 가설 3 을 알 아보기 위해 Baron, Kenny(1996)이 제안한 위계 적 회귀분석을 통해 조절효과를 검증하고, PROCESS MACRO의 Model 1을 이용하여 Aiken 과 West(1991)가 제시한 단순회귀선을 검증 하였다. 마지막으로 가설 4을 알아보기 위해 PROCESS MACRO의 Model 14을 이용하여 조절 된 매개효과를 살펴보았다.

\section{결 과}

\section{상관관계 및 기술통계}

연구에 사용된 변인들의 기술통계, 상관관 계 그리고 왜도 및 첨도의 결과를 표 1 에 제 
Table 1. Descripitve Statistics and Correlations among Variables $(N=697)$

\begin{tabular}{|c|c|c|c|c|c|c|}
\hline & 1 & 2 & 3 & 4 & 5 & 6 \\
\hline 1. Coaching Leadership(CL) & - & & & & & \\
\hline 2. Organizational Trust $(\mathrm{OT})$ & $.55^{* *}$ & - & & & & \\
\hline 3. Innovative Behavior(IB) & $.23^{* *}$ & $.27^{* *}$ & - & & & \\
\hline 4. Power Distance Orientation(PDO) & -.01 & $.09 *$ & $-.09 *$ & - & & \\
\hline 5. Job Postion & .06 & $.13^{* *}$ & $.24^{* *}$ & .02 & - & \\
\hline 6. Age & .02 & $.16^{* *}$ & $.17^{* *}$ & .02 & $.48^{* *}$ & - \\
\hline $\mathrm{M}$ & 2.98 & 3.80 & 3.14 & 2.18 & 2.38 & 2.52 \\
\hline SD & .84 & 1.26 & .66 & .62 & 1.41 & 1.12 \\
\hline 첨도 & -.36 & -.18 & .09 & .17 & -.83 & -1.35 \\
\hline 왜도 & -.26 & -.20 & -.25 & .20 & .67 & -.03 \\
\hline
\end{tabular}

${ }^{*} p<.05$. ${ }^{* *} p<.01$.

시하였다. 왜도와 첨도는 연령을 제외하고 모 두 1 과 -1 사이의 값을 보여 정상성 가정이 충족되었다. 연령의 경우 왜도가 -1.352 를 보 였지만 정상성 가정을 해치지 않는다. 기술통 계 결과, 코칭리더십 $(\mathrm{M}=2.982, \mathrm{SD}=.837)$, 조직신뢰 $(\mathrm{M}=3.801, \mathrm{SD}=1.264)$, 혁신행동 $(\mathrm{M}=3.136, \mathrm{SD}=.664)$, 권력거리성향 $(\mathrm{M}=$ $2.182, \mathrm{SD}=.618)$ 과 직급 $(\mathrm{M}=2.38, \mathrm{SD}=$ 1.41 )의 결과를 나타냈다. 직급은 " $1=$ 사원, $2=$ 대리, $3=$ 과장, $4=$ 차장, $5=$ 부장 “으로, 연령은 "1=만20 29세, 2=만30 39세, 3=만40 49세, $4=$ 만50 59세”로 코딩되었다.

상관분석 결과, 코칭리더십은 조직신뢰 $(r=$ $.55, p<.01)$ 와 혁신행동 $(r=.229, p<.01)$ 과 정적 상관을 보였고, 권력거리성향 $(r=-.011$, $p>.05)$ 과 직급 $(r=-.055, p>.05)$ 과는 모두 상관이 유의하지 않았다. 조직신뢰는 혁신행 동 $(r=.269, p<.01)$, 권력거리성향 $(r=.092$, $p<.05)$, 직급 $(r=.129, p<.01)$, 연령 $(r=$
$.164, p<.01)$ 과 유의미한 정적상관을 보였다. 혁신행동은 권력거리성향 $(r=-.093, p<.05)$ 과 부적 상관을 보였으며, 직급 $(r=.24, p<$ $.01)$ 과 연령 $(r=.171, p<.01)$ 에서는 유의미한 정적 상관을 보였다.

\section{확인적 요인분석}

본 연구에서는 확인적 요인분석(Confirmatory factor analysis, $\mathrm{CFA}$ )을 통하여 변인 간의 판별 타당도를 검증하였다. SPSS 24.0 의 요인분석을 이용하여 코칭리더십, 조직신뢰, 혁신행동, 권 력거리성향의 4 개 변인, 총 36 문항을을 실시 하였다. 요인추출 방법은 주성분 분석, 요인회 전 방법은 베리멕스를 설정하였다. $\mathrm{KMO}$ 값은 .946 , Bartlett의 검정 통계량은 $p<.001$ 수준 으로 나타났다. 요인 적재값은 .5 이상을 기준 으로 하였고, 추출된 4 요인의 누적된 총 분 산은 $62.79 \%$ 를 나타냈다. 


\section{코칭리더십과 혁신행동의 관계}

코칭리더십과 혁신행동이 정적 관계에 있는 지 알아보기 위해 SPSS 24.0 의 선형회귀분석을 통해 위계적 회귀분석을 실시하였다. 혁신행 동과 유의미한 상관을 보였던 인구통계적 변 인인 연령과 직급을 1 단계에서 통제하였고, 2 단계로 코칭리더십을 투입하였다. 회귀모형은 1 단계 $(F=22.696, p<.001), 2$ 단계 $(F=28.1476$, $p<.001)$ 로 모두 통계적으로 유의하게 나타났다. 표 2에서 보이는 봐와 같이 회귀모형의 설명 력은 $10.9 \%\left(R^{2}=.109\right)$ 로 나타났다. DurbinWatson 통계량은 2.019로 독립성 가정을 충족 하였다. 코칭리더십이 혁신행동에 정적인 영 향 $(\beta=.218, p<.001)$ 을 미치는 것으로 나타났 다. 따라서 위의 결과를 통해 가설 1 은 지지 되었다.
코칭리더십과 혁신행동의 관계에서 조직신뢰 의 매개효과

코칭리더십과 혁신행동의 관계에서 조직신 뢰의 매개효과가 있는지 알아보기 위해 Hayes, A. F.(2018)의 PROCESS MACRO의 Model 4을 이용했다. 독립변인으로 코칭리더십, 종속변인 으로 혁신행동, 매개변인으로 조직신뢰 그리 고 통제변인으로 직급을 설정하였다. 통계적 유의성 검증을 위해 Bootstrapping을 5000회 실 시하였으며 $95 \%$ 신뢰수준으로 설정하였다. 표 3 과 그림 2 는 그 결과이다. 1 단계로 코칭리더 십은 조직신뢰에 정적 영향 $(\beta=.546, p<.001)$ 을 미치는 것으로 나타났다. 2단계에서 코칭 리더십이 혁신행동에 미치는 영향 $\beta=.126$, $p<.01)$ 과 조직신뢰가 혁신행동에 미치는 영향 $(\beta=.168, p<.001)$ 모두 정적으로 유의한 것 으로 확인되었다. 따라서 코칭리더십과 혁신

Table 2. The Result of Regression Analysis

\begin{tabular}{ccccc}
\hline \multirow{2}{*}{ Step } & Variables & \multicolumn{3}{c}{ Innovative Behavior } \\
\cline { 3 - 4 } & & $\beta$ & $\mathrm{R}^{2}$ & $\triangle \mathrm{R}^{2}$ \\
\hline 1 & Age, Job Position & & $.06^{* * *}$ & \\
\hline 2 & Coaching Leadership & $.22^{* * *}$ & $.11^{* * *}$ & $.05^{* * *}$ \\
\hline$* * p<.01 .{ }^{* * *} p<.001$. & & &
\end{tabular}

Table 3. The Mediating Effect of Organizational Trust Between Coaching Leadership and Innovative Behavior

\begin{tabular}{|c|c|c|c|c|c|c|c|c|c|}
\hline \multirow{2}{*}{$\begin{array}{c}\text { Independent } \\
\text { Variable }\end{array}$} & \multirow{2}{*}{$\begin{array}{c}\text { Dependent } \\
\text { Variable }\end{array}$} & \multirow{2}{*}{$\beta$} & \multirow{2}{*}{$B$} & \multirow{2}{*}{$S E$} & \multirow{2}{*}{$t$} & \multicolumn{2}{|c|}{$95 \% \mathrm{CI}$} & \multirow{2}{*}{$F$} & \multirow{2}{*}{$\mathrm{R}^{2}$} \\
\hline & & & & & & $\mathrm{LL}$ & UL & & \\
\hline $\mathrm{CL}$ & OT & .55 & .82 & .05 & $17.17^{* * * *}$ & .73 & .92 & 112.34 & .33 \\
\hline $\mathrm{CL}$ & \multirow{2}{*}{ IB } & .13 & .1 & .03 & $2.95 * *$ & .03 & .17 & \multirow{2}{*}{25.29} & \multirow{2}{*}{.13} \\
\hline OT & & .17 & .09 & .02 & $3.87 * * *$ & .04 & .13 & & \\
\hline
\end{tabular}

${ }^{* *} p<.01 .{ }^{* * *} p<.001$. 


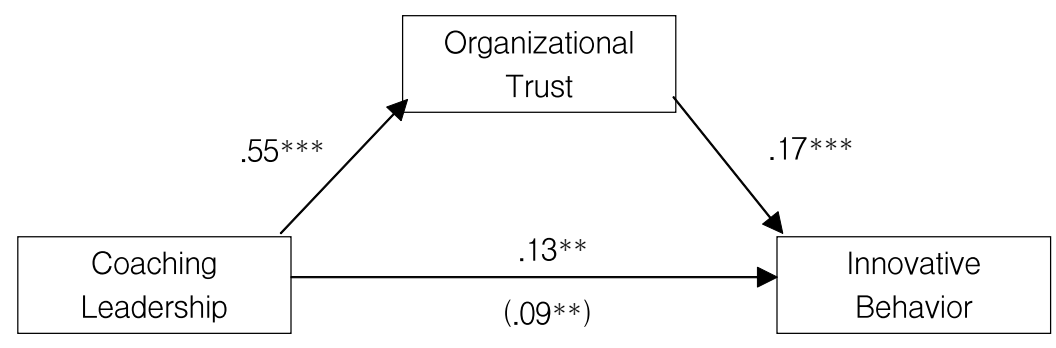

$* * p<.01 . * * * p<.001$.

Figure 2. Standadized Regression Coefficient Indirect Effect in Parenthesis

행동의 관계에서 조직신뢰의 부분매개 효과가 있는 것이 검증되었다. 또한 Bootstrapping을 통 한 조지직신뢰의 간접효과도 검증되었다 $\beta=$ .092, CI[.035, .147]). 위의 결과를 통해 가설 2 은 지지되었다.

조직신뢰와 혁신행동의 관계에서 권력거리성 향의 조절효과

조직신뢰와 혁신행동의 관계에서 권력거리 성향 수준에 따라 차이가 있는지 알아보기 위 해 Baron \& Kenny(1996)이 제안한 위계적 회귀 분석을 통해 조절효과를 검증하였다. 이후,
Hayes, A. F.(2018)의 PROCESS MACRO의 Model 1 을 이용하여 독립변인으로 조직신뢰, 종속변 인으로 혁신행동, 조절변인으로 권력거리성향 그리고 통제변인으로 직급과 연령을 설정하였 다. 다중공선성의 문제를 줄이기 위해 조절효 과에 검증에 사용된 모든 연속형 변수는 평균 중심화를 실시하였다. 또한, 코칭리더십과 권 력거리성향의 구체적인 상호작용을 살펴보기 위해 Aiken과 West(1991)가 제시한 평균 \pm 1 표 준편차를 기준으로 권력거리성향을 구분하였 다. 표 4 는 조절효과의 검증 결과이고, 표 5 는 권력거리성향의 수준에 따른 단순회귀선의 유 의성 검증 결과이다.

Table 4. The Modreating Effect of Power Distance Orientation Between Organizational Trust and Innovative Behavior

\begin{tabular}{|c|c|c|c|c|c|c|c|}
\hline \multirow{2}{*}{ Step } & \multirow{2}{*}{$\begin{array}{c}\text { Independent } \\
\text { Variable }\end{array}$} & \multicolumn{6}{|c|}{ Dependent Variable : Innovative Behavior } \\
\hline & & $\beta$ & $B$ & $S E$ & $t$ & $R^{2}$ & $\Delta R^{2}$ \\
\hline 1 & OT & .24 & .13 & .02 & $6.58^{* * *}$ & $.12^{* * *}$ & $.55 * * *$ \\
\hline \multirow{2}{*}{2} & OT & .25 & .13 & .02 & $6.90^{* * *}$ & \multirow{2}{*}{$.13^{* *}$} & \multirow{2}{*}{$.01^{* *}$} \\
\hline & PDO & -.12 & -.13 & .04 & $-3.35 * *$ & & \\
\hline \multirow{3}{*}{3} & OT & -.07 & -.04 & .06 & -.55 & \multirow{3}{*}{$.14^{* *}$} & \multirow{3}{*}{$.01^{* *}$} \\
\hline & PDO & -.41 & -.44 & .12 & $-3.64 * * *$ & & \\
\hline & $\mathrm{OT} \times \mathrm{PDO}$ & .46 & .08 & .03 & $2.71 * *$ & & \\
\hline
\end{tabular}

${ }^{* *} p<.01 .{ }^{* * *} p<.001$. 
Table 5. Significance of Simple Regression line according to Power Distance Orientation

\begin{tabular}{cccccccc}
\hline & & & & & & \multicolumn{2}{c}{$95 \%$ CI } \\
\cline { 5 - 7 } & & & $S E$ & $t$ & LL & UL \\
\hline \multirow{3}{*}{ Power DIstance } & $-1 \mathrm{SD}$ & .09 & .02 & $3.75^{* * *}$ & .04 & .14 \\
Orientaion & Mean & .14 & .02 & $7.29^{* * *}$ & .10 & .18 \\
& $+1 \mathrm{SD}$ & .19 & .03 & $6.61^{* * *}$ & .13 & .25 \\
\hline
\end{tabular}

$* * * p<.001$.

표 4의 결과를 살펴보면, 직급과 코칭리더 십을 먼저 투입하여 통제변인으로 설정한 후 다른 변인들을 순차적으로 투입하였다. 2단계 에서 조직신뢰와 권력거리성향을 투입하고, 3 단계에서 상호작용항을 추가로 투입하였다. 그 결과, 상호작용항이 통계적으로 유의한 것 으로 나타났으며 $(\beta=.455, p<.01)$ 혁신행동을 $1 \%$ 추가적으로 설명하는 것으로 확인되었다. 또한, 표 5의 결과를 살펴보면 조직신뢰와 혁 신행동의 정적 관계는 권력거리성향의 수준이 높을수록 가파르게 증가하는 경향을 보였다. 위의 결과를 통해 가설 3 은 지지되었다.
코칭리더십, 조직신뢰, 혁신행동의 관계에서 권력거리 성향의 조절된 매개효과

코칭리더십과 혁신행동의 관계에서 조직신 뢰의 매개효과가 권력거리성향의 수준에 따라 차이가 있는지 알아보기 위해 Hayes, A. F. (2018)의 PROCESS MACRO의 Model 14을 이용 하였다. 독립변인으로 코칭리더십, 종속변인으 로 혁신행동, 매개변인으로 조직신뢰, 조절변 인으로 권력거리성향 그리고 통제변인으로 직 급을 설정하였다. 표 6 은 조절된 매개효과의 검증 결과이고, 표 7 은 권력거리성향의 수준

Table 6. Moderated Mediating Effect of Power Distance Orientation by Organizational Trust

\begin{tabular}{|c|c|c|c|c|c|c|}
\hline \multirow{3}{*}{$\begin{array}{c}\text { Independent } \\
\text { Variable }\end{array}$} & \multicolumn{6}{|c|}{ Dependent Variable : Organizational Trust } \\
\hline & \multirow[b]{2}{*}{$B$} & \multirow{2}{*}{$S E$} & \multirow[b]{2}{*}{$t$} & \multirow{2}{*}{$R^{2}$} & \multicolumn{2}{|c|}{$95 \%$ CI } \\
\hline & & & & & $\mathrm{LL}$ & UL \\
\hline \multirow[t]{2}{*}{$\mathrm{CL}$} & .824 & .047 & $17.496^{* * *}$ & $.327^{* * *}$ & .732 & .917 \\
\hline & \multicolumn{6}{|c|}{ Dependent Variable : Innovative Behavior } \\
\hline $\mathrm{CL}$ & .09 & .03 & $2.66^{* *}$ & \multirow{4}{*}{$.15^{* * *}$} & .02 & .16 \\
\hline OT & .11 & .02 & $4.62^{* * *}$ & & .06 & .15 \\
\hline PDO & -.12 & .04 & $-3.25 * *$ & & -.20 & -.05 \\
\hline OT $\times$ PDO & .08 & .03 & $2.65^{* *}$ & & .02 & .14 \\
\hline
\end{tabular}

${ }^{*} p<.05 .{ }^{* *} p<.01 .{ }^{* * *} p<.001$. 
박선규·정은경 / 코칭리더십가 혁신행동의 관계에서 조직신뢰의 매개효가와 권력거리성향의 조절된 매개효가

Table 7. Conditional Indirect Effect according to Power Distance orientation

\begin{tabular}{cccccc}
\hline & & & & \multicolumn{2}{c}{$95 \%$ CI } \\
\cline { 4 - 6 } & & & $S E^{\dagger}$ & LL & UL \\
\hline \multirow{3}{*}{ Power Distance } & $-1 \mathrm{SD}$ & .05 & .03 & -.01 & .10 \\
Orientation & Mean & .09 & .02 & .04 & .13 \\
& $+1 \mathrm{SD}$ & .13 & .03 & .07 & .18 \\
\hline
\end{tabular}

$\dagger^{\dagger} E$ 와 신뢰구간은 9,500번의 Bootstrapping을 통해 추정함.

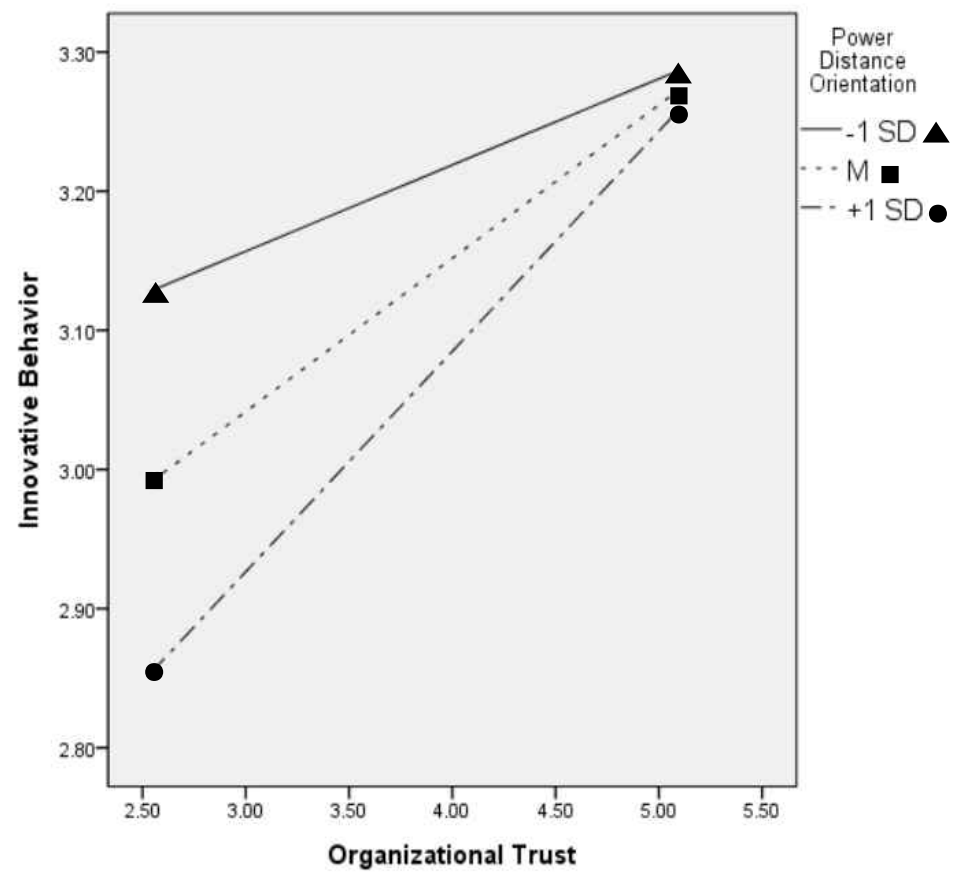

Figure 3. Interaction Effect of Organiztional Trust and Power Distance Orientation on Innovative Behavior

에 따른 간접효과 검증 결과이다. 그림 3 은 단순회귀식의 그래프이다.

표 6에서 결과를 살펴보면 먼저, 코칭리더 십이 조직신뢰에 정적 영향 $(B=.824, p<.001)$ 을 유의하게 미치는 것으로 나타났다. 이후, 코칭리더십, 조직신뢰, 권력거리성향 그리고 조직신뢰와 권력거리성향의 상호작용항을 동
시에 투입하였다. 코칭리더십이 혁신행동에 미치는 직접효과 $(B=.09, p<.01)$ 와 조직신 뢰가 혁신행동에 미치는 간접효과 $(B=.106$, $p<.001)$ 가 유의했다. 마지막으로 조직신뢰와 권력거리성향의 상호작용항이 유의하여 조절 된 매개효과 $(B=.078, p<.01)$ 가 검증되었다.

이어서 조절된 매개효과의 구체적인 양상을 
확인하기 위하여 권력거리성향의 수준을 평균 과 평균 \pm 1 표준편차로 나누었다. 표 7 에서 나타났듯이 권력거리가 낮은 수준(-1SD)에서 신뢰구간(95\% CI [-.012, .102]) 내에 0을 포함 하여 통계적으로 유의하지 않은 것으로 나타 났다. 반면, 권력거리성향이 평균과 높은 수준 $(+1 S D)$ 은 모두 통계적으로 유의한 것으로 나 타났다. 따라서 권력거리수준이 평균일 때와 높은 수준일 때의 조건부 간접효과만이 유의 한 것을 알 수 있다. 그림 3 은 권력거리성향 의 수준에 따른 단순회귀식이다. 코칭리더십, 조직신뢰, 혁신행동의 관계에서 권력거리성향 이 높을수록 조건부 간접효과가 증가(기울기 가 가파름)함을 알 수 있다. 그러나 기본적인 혁신행동의 수행 정도는 권력거리성향이 낮을 수록 높았다. 다시 말해, 코칭리더십, 조직신 뢰, 혁신행동의 관계에서 혁신행동의 수행 자 체는 권력거리성향이 낮은 집단에서 높지만, 코칭리더십과 조직신뢰가 증가할수록 혁신행 동이 증가하는 기울기는 권력거리성향이 높은 수준에서 더욱 가파르다. 위의 결과를 통해 가설 4 은 지지되었다.

\section{논 의}

본 연구는 코칭리더십이 혁신행동에 영향을 미치는 과정에서 조직신뢰가 매개변인으로써 작용함을 검증하고자 했다. 이에 더하여, 조직 신뢰가 혁신행동에 미치는 영향이 구성원의 권력거리성향에 따라 어떻게 달라지는지를 파 악하고자 하였고, 마지막으로 코칭리더십이 조직신뢰를 통해 혁신행동에 영향을 미치는 간접효과에서 권력거리성향의 조절된 매개효 과를 알아보았다. 결과적으로 조직신뢰는 코
칭리더십과 혁신행동의 관계를 매개하는 것으 로 나타났고, 권력거리성향의 조절효과 및 조 절된 매개효과도 유의미한 것으로 확인되었다. 구체적으로, 리더의 코칭리더십이 혁신행동 에 정적인 영향을 미치는 것으로 검증되었다. 이는 코칭리더십의 주요 요인인 방향제시, 개 발, 수행평가, 관계가 혁신행동을 일으키는데 도움이 됨을 나타내며, 이러한 결과는 여러 선행연구의 결과와도 일치한다(Min, 2012; Seo, 2011; Ha \& Tak, 2012). 특히 본 연구에서는 코칭리더십이 혁신행동에 미치는 영향이 조직 신뢰를 통제한 상태에서도 유의하여 코칭리더 십의 고유한 설명변량이 여전히 존재하는 것 으로 나타났다. 또한, 코칭리더십은 조직신뢰 에 정적 영향을 미치는 것으로 나타났다. 코 칭리더십을 통해 리더가 구성원과 신뢰관계를 쌓고 구성원의 능력을 믿어주며, 명확한 목표 제시와 함께 구체적인 피드백을 하는 것이 구 성원들로 하여금 조직을 믿고 의지할 수 있게 끔 만든 것으로 보인다. 다만 코칭리더십이 다른 리더십에 비해 조직신뢰에 미치는 영향 이 더 클지는 본 연구에서 다루지 못하였는데, 각 리더십이 조직신뢰에 미치는 영향력의 크 기를 종합적으로 검토하는 것도 필요할 것으 로 보인다. 더불어, 조직신뢰가 높은 구성원들 은 조직이 자신에게 마땅한 대우를 해줄 것을 기대하고(Whitener, Brodt, Korsgaard, \& Werner, 1998; Kee \& Knox, 1970) 혁신행동에 수반될 수 있는 실패나 손실 위험에 대해서도 조직이 어느 정도 수용할 것이라는 믿음을 갖게 되므 로(Schoorman, Mayer, \& Davis, 2007) 조직신뢰는 위험감수와 관련된 혁신행동에 긍정적인 영향 을 미친 것으로 보인다.

한편, 권력거리성향의 수준에 따라 코칭리 더십이 조직신뢰를 통해 혁신행동에 미치는 
영향의 크기가 다른 것으로 나타났다. 먼저 권력거리성향이 혁신행동에 미치는 영향에서 는 예상대로 권력거리성향의 수준이 낮은 구 성원들이 권력거리성향의 수준이 높은 구성원 들보다 혁신행동을 더욱 많이 하는 것으로 나 타났다. 권력거리성향이 낮은 구성원은 좀 더 자율적으로 업무를 수행하고(Kim \& Moon, 2019) 상급자와의 소통을 통해 자신의 의견을 개진하고 설득할 수 있다고 믿기 때문에 상급 자의 결정이 절대적이라고 생각하는 권력거리 성향이 높은 구성원들보다는 혁신행동을 보일 가능성이 더 높다. 다만, 조직신뢰가 혁신행동 에 미치는 영향은 권력거리성향이 높은 구성 원들에게서 훨씬 강하게 나타났다. 즉 권력거 리성향이 높은 구성원들의 경우 조직신뢰가 높아지면 혁신행동이 급격히 증가하였으나 권 력거리성향이 낮은 구성원들에게는 조직신뢰 가 혁신행동에 미치는 영향이 유의하지 않았 다. 이러한 결과는 권력거리성향이 낮은 수준 의 구성원들은 조직신뢰가 낮더라도 혁신적인 행동을 하는데 충분한 내적 동기가 있기 때문 으로 보인다. 예를 들어, 구성원이 자신이 속 한 집단에 제도적으로 문제가 있다고 생각하 여 조직을 신뢰할 수 없는 상황이라고 한다면, 권력거리성향이 낮은 수준의 구성원은 제도적 문제점을 개선하기 위해 자신의 의견을 리더 에게 적극적으로 반영하려고 노력할 것이다. 이러한 문제해결 과정에서 혁신행동은 자연스 레 일어날 수 있다. 반면, 권력거리성향이 높 은 수준의 구성원은 조직신뢰가 낮을 때는 자 신의 실수나 실패에 대한 문책 가능성을 크게 느끼고 리더가 시키는 것만 하려고 할 것이다. 그러나 조직신뢰가 높아질수록 구성원은 자신 의 실수나 실패에 대한 문책 가능성을 크게 느끼지 않고 리더가 지시한 업무를 자신의 재
량껏 성취하려는 성향이 나타나 혁신행동이 증가할 수 있다. 이러한 결과는 권력거리성향 이 높은 경우 주변 환경의 영향을 더 많이 받는다는 연구(Kim \& Moon, 2019)와 일맥상 통한다.

본 연구는 코칭리더십과 혁신행동간의 관계 에 대한 조직신뢰의 매개효과를 최초로 밝혔 으며, 이러한 매개모델이 개인의 권력거리성 향에 따라 달라진다는 점을 새롭게 밝혔다는 것에 학문적 의의가 있다. 아울러 본 연구의 실무적 시사점은 다음과 같다. 첫째, 코칭리더 십이 구성원의 혁신행동을 증가시키는 것으로 나타난 만큼 조직은 리더들이 코칭리더십을 갖추도록 훈련하는 것을 고려할 필요가 있다. 어느 정도의 인격적 혹은 성격적 변화를 요구 하는 변혁적 리더십이나 진정성리더십, 서번 트리더십과 같은 기존 리더십에 비해 코칭리 더십은 피드백이나 목표설정과 같은 기술적 특성을 많이 포함하는 리더십이다. 이는 리더 들이 코칭리더십을 갖추도록 훈련하는 것이 투여되는 비용 대비 효과성이 큰 접근이 될 수 있음을 의미한다. 따라서 조직은 코칭리더 십의 다양한 효과를 광범위하게 수집하고 좀 더 적극적으로 리더들에게 코칭리더십을 교육 할 필요가 있다. 둘째, 구성원의 혁신행동은 조직신뢰를 증가시킴으로써 부분적으로 증진 될 수 있다. 리더들이 코칭리더십을 습득하는 데 개인차가 존재하고 비교적 오랜시간이 소 요되므로 조직 차원에서는 정책이나 상징 등 을 통해 조직신뢰를 증가시키는 것이 구성원 의 혁신행동을 촉진하는데 도움이 될 것이다 특히 코로나 19 와 같이 사회적으로 불안정하 고 개인의 고용불안이 심한 시기에 구성원들 은 자신의 행동에 대한 위험성을 더욱 크게 지각할 수 있으므로, 조직의 리더는 권력거리 
성향이 높은 구성원들과 의사소통할 때 그들 의 행동에 따른 위험을 리더가 함께 공유하고 있음을 알리고, 신뢰로운 관계를 형성할 수 있도록 노력해야 할 것이다. 마지막으로, 한국 이 권력거리가 상당히 높은 국가임을 고려한 다면(Hofstede, 1983; Yoo, Rao, \& Hong, 2006), 국내 기업이나 조직에서 혁신행동이 자연적으 로 나타날 가능성은 권력거리가 낮은 국가들 보다 낮다. 본 연구결과, 권력거리가 낮은 사 람들의 혁신행동은 조직신뢰에 크게 영향을 받지 않으나 권력거리가 높은 사람들의 혁신 행동은 조직신뢰에 영향을 받으므로 조직은 권력거리가 높은 사람들의 조직신뢰를 높일 수 있는 방법을 연구하여 적용할 필요가 있다. 예를 들면, 혁신행동에 의한 실패를 처벌하지 않고 혁신행동 그 자체에 보상한다는 명확한 정책발표 및 실제 사례 공유는 권력거리가 높 은 사람들의 조직정책에 대한 신뢰성을 높여 혁신행동을 할 수 있도록 촉진할 수 있다.

본 연구의 한계점과 향후 연구의 방향성은 다음과 같다. 첫째, 본 연구가 자기보고식 검 사만을 사용하여 이루어졌다는 점이다. 특히 혁신행동의 경우, 객관적 평가가 아닌 주관적 자기보고이므로 편향이 존재할 수 있다. 따라 서 향후 연구에서는 구성원의 혁신행동을 측 정하는데 있어 좀 더 객관성을 확보할 수 있 도록 다면적인 평가를 이용할 것을 제안한다. 둘째, 횡단적 연구설계로 인해 인과관계 해석 에 제한이 있다는 것이다. 추후 연구에서는 코칭리더십이 혁신행동을 증가시키는 데 있어 서 시점 간 변화를 살펴 인과관계를 더욱 명 학히 밝혀야 할 것이다. 셋째, 본 연구에서는 조절변인으로 권력거리성향을 설정하여 조절 된 매개효과를 살펴봤다. 그러나 이외에도 혁 신행동을 조절하는 변인이 많을 수 있다. 따
라서 개인주의와 집단주의 혹은 불확실성회피 성향 같은 개인이 가진 다른 속성들에 따라 어떠한 영향을 미치는지 살펴 더욱 구체적인 연구가 이뤄져야 할 것이다. 넷째, 본 연구는 한국인만을 대상으로 하여 결과 일반화에 한 계를 갖는다. 권려거리는 문화의 영향을 많이 받는 변인이므로 동일한 연구를 다른 문화권 에서도 반복검증해볼 필요가 있다.

상기한 제한점에도 불구하고 본 연구는 4 차 산업시대에 더욱 중요성이 증가하는 구성원의 혁신행동에 영향을 미치는 리더의 특성과 그 매커니즘, 그리고 이를 조절하는 구성원의 특 징을 권력거리성향을 통해 처음으로 살펴보았 다는 데 그 의의가 있다.

\section{참고문헌}

Amabile, T. M. (1983). The social psychology of creativity: A componential conceptualization. Journal of personality and social psychology, 45(2), 357-376.

https://doi.org/10.1037//0022-3514.45.2.357

Anderson, M. C., Frankovelgia, C., \& Hernez Broome, G. (2009). In focus/coaching: Business leaders reflect on coaching cultures. Leadership in Action: A Publication of the Center for Creative Leadership and Jossey Bass, 28(6), 20-22. https://doi.org/10.1002/lia.1273

Appelbaum, N. P., Lockeman, K. S., Orr, S., Huff, T. A., Hogan, C. J., Queen, B. A., \& Dow, A. W. (2020). Perceived influence of power distance, psychological safety, and team cohesion on team effectiveness. Journal of interprofessional care, 34(1), 20-26. 
https://doi.org/10.1080/13561820.2019.1633290

Arnold, J. A., Arad, S., Rhoades, J. A., \&

Drasgow, F. (2000). The Empowering

Leadership Questionnaire: the construction and validation of a new scale for measuring leader behaviors. Journal of Organizational Behavior, 21(3), 249-269.

https://doi.org/10.1002/(SICI)1099-1379(200005) 21:3<249::AID-JOB10>3.0.CO;2-\#tionnaire: The Construction and Validation of a New Scale for Measuring Leader Behaviors", Journal of Organizational Behavior, 21, 249-269.

Aryee, S., Budhwar, P. S., \& Chen, Z. X. (2002).

Trust as a mediator of the relationship between organizational justice and work outcomes: Test of a social exchange model. Journal of Organizational Behavior: The International Journal of Industrial, Occupational and Organizational Psychology and Behavior, 23(3), 267-285. https://doi.org/10.1002/job.138

Battistelli, A., Montani, F., \& Odoardi, C. (2013). The impact of feedback from job and task autonomy in the relationship between dispositional resistance to change and innovative work behaviour. European Journal of Work and Organizational Psychology, 22(1), 26-41.

https://doi.org/10.1080/1359432X.2011.616653.

Cho, E. H., \& Tak, J. K. (2011). Development and Validity of the Coaching Leadership Scale. Korean Journal of Industrial and Organizational Psychology, 24(1), 127-155.

http://dx.doi.org/10.24230/ksiop.24.1.201102.127

Choi, I. O., Park, J. H., \& Sun, J. G. (2011). A Study on the Relationship between
Organizational Culture and Innovative Behaviors of Organizational Members: The Moderating Effect of Organizational Trust and Task Conflict. The Journal of Business and Economics, 27(3), 1-33. https://doi.org/10.22793/indinn.2011.27.3.001

Cook, J., \& Wall, T. (1980). New work attitude measures of trust, organizational commitment and personal need non fulfilment. Journal of occupational psychology, 53(1), 39-52. https://doi.org/10.1111/j.2044-8325.1980.tb000 $05 . \mathrm{x}$

Costa, A. C. (2003), Work team trust and effectiveness. Personnel Review, 32(5), 605-622. https://doi.org/10.1108/00483480310488360

Dai, Y. (2019). Coaching Leadership, Job Motivation and Employee Innovation Behavior. In 5th Annual International Conference on Social Science and Contemporary Humanity Development, 592-597. https://doi.org/10.2991/sschd-19.2019.120.

Dorfman, P. W., \& Howell, J. P. (1988). Dimensions of national culture and effective leadership patterns: Hofstede revisited. Advances in international comparative management, 3(1), 127-150

Drucker, P.F. (1988). The Coming of the New Organization. Harvard Business Review, 66, 45-53.

Edmondson, A. (1999). Psychological safety and learning behavior in work teams. Administrative science quarterly, 44(2), 350-383. https://doi.org/10.2307/2666999

Ellinger, A. D., \& Bostrom, R. P. (1999). Managerial coaching behaviors in learning 
organizations. Journal of Management Development, 18(9), 752-771.

https://doi.org/10.1108/02621719910300810

Ellinger, A. D., Ellinger, A. E., \& Keller, S. B. (2003). Supervisory coaching behavior, employee satisfaction, and warehouse employee performance: A dyadic perspective in the distribution industry. Human resource development quarterly, 14(4), 435-458.

https://doi.org/10.1002/hrdq.1078

Farh, J. L., Hackett, R. D., \& Liang, J. (2007). Individual-level cultural values as moderators of perceived organizational support-employee outcome relationships in China: Comparing the effects of power distance and traditionality. Academy of management journal, 503), 715-729. https://doi.org/10.5465/amj.2007.25530866

Fox, A. (1974). Beyond contract: Work, power and trust relations. Faber \& Faber.

Glassman, E. (1986). Managing for creativity: Back to basics in $\mathrm{R} \& \mathrm{D} . \mathrm{R} \& D$ Management, $16(2)$, 175-183.

https://doi.org/10.1111/j.1467-9310.1986.tb011 70. $\mathrm{x}$

Goodwin, J., \& Goodwin, D. (1999). Ethical Judgments Across Cultures: A Comparison between Business Students from Malaysia and New Zealand. Journal of Business Ethics, 3(18), 267-281.

https://oi.org/10.1023/A:1005785020162

Gudykunst, W. B., \& Ting-Toomey, S. (1988).

Culture and affective communication. American

behavioral scientist, 31(3), 384-400.

https://doi.org/10.1177/000276488031003009

Guo, S. H. (2018). The Effects of Power Distance between Manager and Employee on Knowledge Hiding Behavior: Focusing on Moderating Effect of Distributive and Procedural Justice. (Master's thesis). Hoseo University, Chungcheongnam-do, Korea.

Ha, W., \& Tak, J. (2012). The effect of coaching leadership on contextual performance and creative behavior: The moderating effects of organizational virtuousness and goal orientation. Korean Journal of Industrial and Organizational Psychology, 25(1), 195-213. https://doi.org/10.24230/kjiop.v25i1.195-213

Hayes, A. F. (2018). Partial, conditional, and moderated moderated mediation: Quantification, inference, and interpretation. Communication monographs, 85(1), 4-40. https://doi.org/10.1080/03637751.2017.1352100

Heslin, P. A., Vandewalle, D. O. N., \& Latham, G. P. (2006). KEEN TO HELP? MANAGERS'IMPLICIT PERSON THEORIES AND THEIR SUBSEQUENT EMPLOYEE COACHING. Personnel psychology, 59(4), 871902.

https://doi.org/10.1111/j.1744-6570.2006.00057.x

Hofstede, G. (1980). Culture and organizations. International studies of management \& organization, $10(4), 15-41$. https://doi.org/10.1080/00208825.1980.11656300

Hofstede, G. (1983). National cultures in four dimensions: A research-based theory of cultural differences among nations. International Studies of Management \& Organization, 13(1-2), 46-74. https://doi.org/10.1080/00208825.1983.11656358

Hofstede, G. (2001). Culture's consequences: Comparing values, behaviors, institutions and organizations 
across nations. Sage publications.

Hwang, C. Y. (2017). The effect of coaching leadership on perceived information system quality, satisfaction, and performance. (Master's thesis). Korea University, Seoul, Korea.

Janssen, O. (2000). Job demands, perceptions of effort reward fairness and innovative work behaviour. Journal of Occupational and organizational psychology, 73(3), 287-302. https://doi.org/10.1348/096317900167038

Javidan, M., Dorfman, P. W., De Luque, M. S., \& House, R. J. (2006). In the eye of the beholder: Cross cultural lessons in leadership from project GLOBE. Academy of management perspectives, 20(1), 67-90. https://doi.org/10.5465/amp.2006.19873410

Javidan, M., House, R. J., Dorfman, P. W., Hanges, P. J., \& de Luque, M. S. (2006). Conceptualizing and measuring cultures and their consequences: a comparative review of GLOBE's and Hofstede's approaches. Journal of International Business Studies, 376), 897-914. https://doi.org/10.1057/palgrave.jibs.8400234

Jeong, Y. R., \& Chung, E. K. (2019). Effects of Supervisors' Power Distance Orientation on Employees' Unethical Pro-Organization Behavior and Somatization: Mediating Effect of Job Stress and Moderating Effect of Job Engagement. Korean Corporation Management Review, 26(6), 29-50.

Jo, I. H. (2016). The effect of coaching leadership on the job engagement and job performance. (Master's thesis). Korea University, Seoul, Korea.

Johnson-George, C., \& Swap, W. C. (1982).
Measurement of specific interpersonal trust: Construction and validation of a scale to assess trust in a specific other. Journal of personality and social psychology, 43(6), 1306. https://doi.org/10.1037/0022-3514.43.6.1306

Kang, M. J., \& Jung, M. S. (2019). Analysis of the Domestic Research Trends on the Coaching Leadership. The Journal of Humanities and Social science, 104), 339-352. https://doi.org/10.22143/HSS21.10.4.25

Kang, S. M. (2020). The Structural Relationships between Hotel Employees'Grit, Job Crafting and Innovative Behavior. Tourism Research, 45(4), 1-17.

https://doi.org/10.32780/ktidoi.2020.45.4.1

Kanter, R. M. (1988). Three tiers for innovation research. Communication Research, 15(5), 509523. https://doi.org/10.1177/009365088015005001

Kanter, R. M. (1988). When a thousand flowers bloom: Structural, collective, and social conditions for innovation in organizations. Knowledge Management and Organisational Design, 10, 93-131.

Kark, R., \& Carmeli, A. (2009). Alive and creating: The mediating role of vitality and aliveness in the relationship between psychological safety and creative work involvement. Journal of Organizational Behavior, 3a6), 785-804. https://doi.org/10.1002/job.571

Kee, H. W., \& Knox, R. E. (1970). Conceptual and methodological considerations in the study of trust and suspicion. Journal of conflict resolution, 14(3), 357-366. https://doi.org/10.1177/002200277001400307 
Kim, J. Y. (2013). The Relationship of Coaching Leadership, Intention to Leave and Organizational Trust among Eye Clinic Employees. (Master's thesis). Inje University, Gyeongsangnam-do, Korea.

Kim, J. S. (2018). Influences of Proactive Personality on Innovative Work Behavior: Moderations by Power Distance. Journal of Human Resource Management Research, 25(2), 41-59.

http://dx.doi.org/10.14396/jhrmr.2018.25.2.41

Kim, M. K. (2011). The effect of the leader coaching behavior in the relationship between job engagement and innovative behavior. (Master's thesis). Korea University, Seoul, Korea.

Kim, M. K., Moon, J. S. (2019). Inclusive Leadership and Creative Performance: The Role of Psychological Safety, Feedback-Seeking Behavior, and Power-Distance. Korean Journal of Human Resources Development, 224), 181-205. https://doi.org/10.24991/KJHRD.2019.12.22.4.1 81

Kim, W. B., \& Rhee, K. Y. (2002). Trust, Social Capital and Organizational Commitment. Korean Journal of Sociology, 36(3), 1-23.

Kim, Y. J. (2005). A study on the impact of Job stress on Innovative Behavior. (Master's thesis) Kyungnam University, Gyeongsangnam-do, Korea.

Kirkman, B. L., Chen, G., Farh, J. L., Chen, Z. X., \& Lowe, K. B. (2009). Individual power distance orientation and follower reactions to transformational leaders: A cross-level, crosscultural examination. Academy of management journal, 52(4), 744-764.

https://doi.org/10.5465/amj.2009.43669971

Konczak, L. J., Stelly, D. J., \& Trusty, M. L. (2000). Defining and measuring empowering leader behaviors: Development of an upward feedback instrument. Educational and Psychological Measurement, 60(2), 301-313. https://doi.org/10.1177/00131640021970420

Kwon, J. U., \& Kwon, S. J. (2015). The Intermediation of Self-Efficiency Between Empowering Leadership and Innovation Behavior. Corporate Education and Human Resources Research, 17(1), 83-103.

Kwon, M. K. (2013). A Study on Airline Employee's Coaching Leadership, ServiceAttitude, and Innovation Behavior. (Doctor's thesis). Kyunggi University, Kyunggi-do, Korea.

Lee Cunningham, J., Gino, F., Cable, D., \& Staats, B. (2020). Seeing oneself as a valued contributor: social worth affirmation improves team information sharing. Academy of Management Journal. https://doi.org/10.5465/amj.2018.0790

Lee, D. S. (2015). Effects of perceived organizational support and role-model on organizational commitment and turnover intention: a focus on mediating effects of organizational trust and self-efficacy. (Master's thesis). Kyunghee University, Seoul, Korea.

Lee, H. E., \& Jeon, J. H. (2016). The Moderating Effect of Power Distance Orientation on the Relationship between Psychological Empowerment, Organizational Commitment, and Turnover Intention. Korean Jouranl of Business Administration, 2912), 1919-1938. 
https://doi.org/10.18032/kaaba.2016.29.12.1919

Lee, H., \& Kim, J. H. (2017). Effects of the Power Distance Orientation of Overseas Salesperson on Emotional Labor and Sales Performance. Journal of International Trade \& Commerce, 13(3), 605-621.

http://dx.doi.org/10.16980/jitc.13.3.201706.605

Lee, S. Y. (2018). The effect of SME CEO leadership type and organizational culture on organizational effectiveness: focusing on mediating effect of job crafting. (doctor's thesis). Hoseo University, Chungcheongnam-do, Korea.

Lim, K. H. (2017). A study on the Effects of Authorized Leadership on police Mid-level Manager on Job attitude and Organizational commitment: Focused on Job crafting mediation effect (doctor's thesis). Hansei University, Gyunggi-do, Korea

Liu, W. (2016). The Effect of Leader's Coaching Leadership on The Burnout of Employee. (Master's thesis). Korea University of technology \& education, Chungcheongnam-do, Korea.

Livingston, J. 1969. Pygmalion in management. Harvard Business Review, 47(4), 81-89.

Mayer, R. C., Davis, J. H., \& Schoorman, F. D. (1995). An integrative model of organizational trust. Academy of management review, 20(3), 709-734.

https://doi.org/10.5465/amr.1995.9508080335

McCauley, D. P., \& Kuhnert, K. W. (1992). A theoretical review and empirical investigatiomn of employee trust in management. Public Administration Quarterly, 16(5) 265-284.
McLean, G. N., Yang, B., Kuo, M. H. C., Tolbert, A. S., \& Larkin, C. (2005). Development and initial validation of an instrument measuring managerial coaching skill. Human Resource Development Quarterly, 16(2), 157-178. https://doi.org/10.1002/hrdq.1131

Min, S. J. (2012). Effects of S insurance company Leader's Coaching Behavior on Members' Innovative Behavior. (Master's thesis). Korea University, Seoul, Korea.

Oh, H. S. (2012). The Effect of coaching leadership on organizational commitment: the mediating effect of trust in manager. (Master's thesis). Kwangwoon University, Seoul, Korea.

Park, G. J., \& Sohn, Y. W. (2009). The Relationship of Empowering Leader Behavior to Team Learning Behavior and Team Transactive Memory: Team efficacy, Support for innovation, and Trust to leader as Mediators. Korean Journal of Industrial and Organizational Psychology, 22(1), 1-25. https://doi.org/10.24230/ksiop.22.1.200902.1

Park, J. C., \& Kwon, B. H. (2021). Structural Relationship between Inclusive Leadership of the Boss, Power Distance, Psychological Safety, Innovation Behavior of Hotel Enterprise Employees. Journal of Hotel \& Resort, 20(2), $47-65$.

Park, J. H., \& Yoon, B. S. (2018). A Study on the Effect of Coaching Leadership on the Organizational Commitment: Mediating Effect of Organizational Trust. Journal of CEO and Management Studies, 21(1), 373-198.

Park, J. H., \& Yoon, B. S. (2016). The Effect of 
the Coaching Leadership on the Organizational Citizenship Behavior: Mediating Effect of Trust. The Korean Society of Management Consulting, 16(1), 35-49.

Park, M. J. (2018). Structural Relationship among the Variables of Coaching Leadership, Innovative Behavior, Job Engagement, and Organization Commitment. Chungang University, Seoul, Korea.

Park, S., McLean, G. N., \& Yang, B. (2008). Revision and Validation of an Instrument Measuring Managerial Coaching Skills in Organizations. Online Submission.

Pelz, D. C., \& Andrews, F. M. (1966). Scientists in organizations: Productive climates for research and development.

Pieterse, A. N., Van Knippenberg, D., Schippers, M., \& Stam, D. (2010). Transformational and transactional leadership and innovative behavior: The moderating role of psychological empowerment. Journal of organizational behavior, 31(4), 609-623. https://doi.org/10.1002/job.650

Rauniyar, K., Ding, D., \& Rauniyar, N. (2017). Understanding the role of creative self-efficacy and power distance orientation for examining the consequences of abusive supervision on employee creativity: a case study from Nepal. Open Journal of Leadership, Q(2), 61-81. https://doi.org/10.4236/oj1.2017.62004

Raza, B., Ali, M., Ahmed, S., \& Moueed, A. (2017). Impact of managerial coaching on employee performance and organizational citizenship behavior: Intervening role of thriving at work. Pakistan Journal of Commerce and Social Sciences, 11(3), 790-813.
Schoorman, F. D., Mayer, R. C., \& Davis, J. H. (2007). An integrative model of organizational trust: Past, present, and future. Academy of Management Review, 32(2), 344-354. https://doi.org/10.5465/amr.2007.24348410

Scott, S. G., \& Bruce, R. A. (1994). Determinants of innovative behavior: A path model of individual innovation in the workplace. Academy of management journal, 373), 580-607. https://doi.org/10.2307/256701

Seo, D. G. (2011). The influence of coaching leadership on the Employees' Job commitment and innovative behavior. (Master's thesis). Hanyang University, Seoul, Korea.

Shalley, C. E., Zhou, J., \& Oldham, G. R. (2004). The Effects of Personal and Contextual Characteristics on Creativity: Where Should We Go from Here?. Journal of Management, 306), 933-958.

https://doi.org/10.1016/j.jm.2004.06.007

Smith, P. B., Peterson, M. F., \& Schwartz, S. H. (2002). Cultural values, sources of guidance, and their relevance to managerial behavior: $\mathrm{A}$ 47-nation study. Journal of cross-cultural Psychology, 33(2), 188-208. https://doi.org/10.1177/0022022102033002005

Song, J. S. (2019). The Effect of Shared Leadership on Organizational Trust, Knowledge Sharing and Innovative Behavior. Journal of the Korea contents assosiation, 199), 485-500. http://dx.doi.org/10.5392/JKCA.2019.19.09.485

Song, U. S., \& Kim, Y. B. (2010). The Relationship between Organizational Trust and Innovational Behavior: Focusing on the Mediation Impacts of the Organizational 
Commitment. Social Science Research Review, 26(3), 127-151.

Stowell, S. J. (1986). Leadership and Coaching, University of Utah (Doctoral dissertation, Ph. D. Dissertation).

Sue-Chan, C., \& Ong, M. (2002). Goal assignment and performance: Assessing the mediating roles of goal commitment and self-efficacy and the moderating role of power distance. Organizational Behavior and Human Decision Processes, 89(2), 1140-1161. https://doi.org/10.1016/S0749-5978(02)00017-1

Sung, H., \& Tak, J. (2017). The effect of coaching leadership on creative behavior: The mediating effect of psychological empowerment. Korean Journal of Industrial and Organizational Psychology, 30(3), 373-391.

https://doi.org/10.24230/kjiop.v30i3.373-391

Tan, H. H., \& Tan, C. S. (2000). Toward the differentiation of trust in supervisor and trust in organization. Genetic, social, and general psychology monographs, 126(2), 241.

Thomas, K. W., \& Velthouse, B. A. (1990). Cognitive Elements of Empowerment: An Interpretive Model of Intrinsic Task Motivation. Academy of Management Review, 15(4), 666-681. https://doi.org/10.5465/amr.1990.4310926.

Volmer, J., Spurk, D., \& Niessen, C. (2012). Leader - member exchange (LMX), job autonomy, and creative work involvement. The Leadership Quarterly, 23(3), 456-465. https://doi.org/10.1016/j.leaqua.2011.10.005

Wang, Y. L. (2013). R\&D employees' innovative behaviors in $\mathrm{T}$ aiwan: HRM and managerial coaching as moderators. Asia Pacific Journal of

Human Resources, 51(4), 491-515. https://doi.org/10.1111/j.1744-7941.2012.00049.x

We, H. K., Kim, I., \& Ryu, T. M. (2018). The Influence of Shared Leadership on Innovative Behavior: Mediated Effect of Organizational Trust. Journal of Human Resource Management Research, 25(5), 103-126.

http://dx.doi.org/10.14396/jhrmr.2018.25.5.103

West, M. A., \& Farr, J. L. (1989). Innovation at work: Psychological perspectives. Social behaviour. Social behaviour, 4(1), 15-30.

Whitener, E. M., Brodt, S. E., Korsgaard, M A., \& Werner, J. M. (1998). Managers as initiators of trust: An exchange relationship framework for understanding managerial trustworthy behavior. Academy of management review, 23(3), 513-530.

https://doi.org/10.5465/amr.1998.926624

Yang, I. S., Lee, S. H., \& Lee, D. R. (2015). A Study on the Effects of Coaching Leadership on Organizational Effectiveness - The Mediating Role of Subordinates' Emotional Intelligence. Journal of Human Resource Management Research, 22(5), 49-72. https://doi.org/10.14396/jhrmr.2015.22.5.49

Yoo, B. H. (2012). An Effect of Learning Orientation on Firm Performance: Focusing on Customer Orientation and Innovativeness. Korean Journal of Business Administration, 25(6), 2809-2826.

Yoo, D. K., Rao, S. S., \& Hong, P. (2006). A comparative study on cultural differences and quality practices - Korea, USA, Mexico, and Taiwan. International Journal of Quality \& 
Reliability Management, 23(6), 607-624. https://doi.org/10.1108/02656710610672452

Yu, M. C., Mai, Q., Tsai, S. B., \& Dai, Y. (2018). An empirical study on the organizational trust, employee-organization relationship and innovative behavior from the integrated perspective of social exchange and organizational sustainability. Sustainability, 103), 864. https://doi.org/10.3390/su10030864

Yuan, F., \& Woodman, R. W. (2010). Innovative behavior in the workplace: The role of performance and image outcome expectations. Academy of management journal, 53(2), 323-342. https://doi.org/10.5465/amj.2010.49388995

Zhang, X. (2020). The Relationship of Coaching Leadership and Innovation Behavior: Dual Mediation Model for Individuals and Teams across Levels. Open Journal of Leadership, 9(1), 70-83

https://doi.org/10.4236/ojl.2020.91005.
Zhou, J., \& Shalley, C. E. (2003). Research on employee creativity: A critical review and directions for future research. Research in personnel and human resources management, 22, 165-217. https://doi.org/10.1016/S0742-7301(03)22004-1 MONEYTODAY (2020, March 25), 화상회의 재택근무 - 유연근무제...일터를 바꾼 코로 나19. MONEYTODAY.

https://news.mt.co.kr/mtview.php?no=20200324 18374243433
투고일자 : 2021. 04. 13. 수정일자 : 2021. 06. 07. 확정일자 : 2021. 07. 02. 


\title{
The effect of Coaching Leadership on Organizational Trust and Innovative Behavior: Moderated Mediation by Power Distance Orientation
}

\author{
Seon Kyu Park \\ Eun Kyoung Chung \\ Department of Psychology, Kangwon National University
}

\begin{abstract}
The purpose of this study is to reveal the effect of coaching leadership on organizational trust and innovative behavior depending on the level of power distance orientation. Specifically, the relationship between coaching leadership and innovative behavior was examined and the mediating effect of organizational trust was identified in the effect of coaching leadership on innovative behavior. In addition, this study examined a moderating effect of power distance orientation on the relationship between organizational trust and innovative behavior Finally, the relationship between coaching leadership and innovative behavior is verified by the moderated mediating effect of power distance orientation in the mediation of organizational trust. For this purpose, data from 697 Korean workers were collected through Embrain, an Internet survey company in Korea. According to the research, the relationship between coaching leadership and innovative behavior has been proven to have a partial mediating effect significantly by organizational trust. The moderating effect of the power distance orientation and the moderated mediating effect were also both significant. Employees with lower organizational turst and lower power distance orientation tended to innovate more than employees with higher power distance orientation, but the difference was found to have been decreased significantly at a higher level of organizational trust. Finally, we discussed practical implications, limitations, and future research.
\end{abstract}

Key words : coaching leadership, organizational trust, innovative behavior, power distance orientation, moderated mediating effect 